\title{
¿LA CORTE CONSTITUCIONAL COMO REFERENTE DEL BUEN VIVIR?'1
}

Carolina Delgado Esguerra²

THE CONSTITUTIONAL COURT AS A REFERENCE OF GOOD LIVING?

A CORTE CONSTITUCIONAL COMO REFERENTE DO BOM VIVER?

Fecha de recepción: 30 de noviembre del 2020

Fecha de aceptación: $1 .^{\circ}$ de marzo del 2021

Disponible en línea: 26 de abril del 2021

Sugerencia de citación. Delgado Esguerra, C. (2021). ¿La corte constitucional como referente del buen vivir?. Razón Crítica, (11), 129-150. https://doi.org/10.21789/25007807.1693

(1) Artículo de reflexión no vinculado a un proyecto de investigación. Se escribió a partir de algunas consideraciones contenidas en el proyecto de tesis doctoral Una historia inconclusa de la lucha por el agua y el modelo de desarrollo en Cajamarca (Tolima), como requisito parcial para acceder al título de doctora en Ciencias Sociales y Humanas en la Pontificia Universidad Javeriana (Bogotá, Colombia).

(2) Abogada de la Pontificia Universidad Javeriana, Especialista en Tributación. Universidad de los Andes, Magister en Historia Económica. Universidad de Barcelona | Estudiante del Doctorado en Ciencias Sociales y Humanas - Pontificia Universidad Javeriana, Colombia delgado.carolina@javeriana.edu.co | https://orcid.org/0000-0003-3279-1516 


\section{R E S U M E N}

A pesar de su diversidad étnica y cultural, Colombia no se presenta como referente del buen vivir en los ámbitos académico o político. Por esto, el presente trabajo busca analizar la existencia de los postulados del buen vivir a partir del estudio de tres pronunciamientos de la Corte Constitucional colombiana en los que se han resuelto conflictos sobre el modelo de desarrollo. Se puede anticipar que, en estos fallos, la Corte ha apostado por elementos afines al buen vivir, implícita o explícitamente, mediante una crítica a la irreflexibidad economicista con la que se asume el proyecto de desarrollo extractivo colombiano y el respaldo que otorgó a las diversas formas de vida de las comunidades involucradas en estos conflictos.

PALABRAS CLAVE: Modelo de desarrollo;

capitalismo; extractivismo; buen vivir;

Corte Constitucional. 


\section{A B S T R A C T}

Despite its ethnic and cultural diversity, Colombia is not a benchmark for good living in the academic or political spheres. Therefore, this work seeks to determine the existence of the postulates of good living based on the study of three decisions by the Colombian Constitutional Court in which conflicts over the national development model were resolved. We can anticipate that, in these rulings, the Court has opted for elements related to good living, implicitly or explicitly, as depicted in the criticism towards the economic lack of reflexibility with which the Colombian extractive development project is assumed and in the support granted to the various ways of life in the communities involved in these conflicts.

Keywords: Development model; capitalism; extractivism; good living; Constitutional Court.

\section{R E S U M O}

Apesar de sua diversidade étnica e cultural, a Colômbia não é referência do bom viver nos contextos acadêmico ou político. Por isso, neste trabalho, pretende-se analisar a existência dos princípios do bom viver a partir do estudo de três pronunciamentos da Corte Constitucional colombiana nos quais são resolvidos conflitos sobre o modelo de desenvolvimento. Pode-se antecipar que, nessas decisões, a Corte apostou por elementos afins ao bom viver, implícita ou explicitamente, mediante uma crítica à irracionalidade economicista com a qual são assumidos o projeto de desenvolvimento extrativo colombiano e o apoio que outorgou às diversas formas de vida das comunidades envolvidas nesses conflitos.

PALAVRAS-CHAVE: modelo de desenvolvimento; capitalismo; extrativismo; bom viver; Corte Constitucional. 
La crítica a la ideología del 'progreso' — crecimiento económico o desarrollo- establece que el sistema impulsado en Latinoamérica a finales del siglo xx es limitado y tiene unas consecuencias determinadas, no solo humanas y sociales, sino con daños irreversibles a la biósfera terrestre que solo son analizados desde la perspectiva de 'costes' (Castoriadis, 1991). A su vez, Rasch $(2012,2017)$ considera que la lucha contra los megaproyectos minero-energéticos, a través de los cuales ha tomado forma el desarrollo económico en Latinoamérica, es una continuación de la resistencia al colonialismo, el genocidio y el neocolonialismo.

Los movimientos sociales han permitido visibilizar modelos alternativos al desarrollo a partir de la crisis del sistema capitalista. La movilización social es la respuesta a las amenazas que representan formas particulares de desarrollo económico sobre la seguridad e integridad de los medios de vida de las comunidades, y la capacidad de una población para controlar sus recursos (Rasch, 2012, 2017).

En ocasiones, estos movimientos sociales promueven la creación de caminos mediante la participación en procesos institucionales (Walter \& Urkidi, 2017). Un ejemplo de esta vía es el uso de recursos institucionales formales, como las acciones de tutela y las consultas populares, lo que ha permitido la discusión jurídica y política sobre la realización de proyectos minero-energéticos al interior de pequeñas comunidades. En virtud de lo anterior, la Corte Constitucional, en diversas intervenciones, ha resuelto, en el fondo, conflictos por el modelo de desarrollo: la Corte ha actuado como árbitro en problemas que involucran intereses económicos extractivos frente a comunidades para quienes el discurso del desarrollo puede ser incompatible con sus modos de vida.

En Latinoamérica, el buen vivir se ha erigido como un concepto posdesarrollista paradigmático para las comunidades indígenas andinas de Ecuador, Bolivia y Perú. Este modelo alternativo al desarrollo hace 
parte de las tendencias que, tanto en el Norte como en el Sur global, "[...] no solo demandan matices de significado para el desarrollo, sino que buscan deconstruirlo para exponer el colonialismo que subyace a las teorías del desarrollo y ampliar el horizonte para incluir múltiples alternativas contextualizadas" (Villalba, 2013, p. 1.428). En Colombia, paradójicamente, a pesar de la diversidad étnica y cultural, no se encuentran referentes específicos sobre el buen vivir en los ámbitos político o académico. Sin embargo, la Corte Constitucional, a partir de los postulados de la Constitución de 1991, ha cuestionado el concepto de 'desarrollo' al referirse a la protección que merecen diversas comunidades y el medio ambiente, en el marco del estado social de derecho.

A partir de lo anterior, como hipótesis, este trabajo plantea que la Corte Constitucional en algunos fallos ha actuado como referente de este modelo alternativo al desarrollo en Colombia. Se entiende el buen vivir en el sentido amplio expuesto por Gudyinas (2011), como se expondrá en la tercera sección.

Para desarrollar esta idea, este artículo de reflexión se estructura en cinco secciones, incluyendo esta introducción: en la segunda sección, se plantea la problematización del concepto de 'desarrollo'; en la tercera sección, se presentan los elementos principales del buen vivir; en la cuarta, se analizan tres fallos de la Corte Constitucional para presentar el conflicto sobre el modelo de desarrollo que subyace en las decisiones y la apuesta de la Corte en materia de buen vivir, y, en la quinta sección, se presentan las conclusiones.

\section{SOBRE EL DESARROLLO ECONÓMICO CAPITALISTA}

A partir de la segunda mitad del siglo xx se impuso la noción de 'desarrollo' como un programa geopolítico de la era poscolonial, caracterizado por ser un modelo linear, unidireccional, impulsado por la comodificación y los mercados capitalistas (Kothari et al., 2019). Este concepto de 'desarrollo' se entiende, en este artículo, como parte de la concepción de 'capitalismo del milenio' o 'capitalismo neoliberal', acuñado por Comaroff \& Comafoff (2000), y el cual refiere al modelo económico capitalista, acompañado por la liberalización o desregulación de los mercados, y, para el cual, la democracia representativa es el 
modelo político por excelencia ${ }^{3}$. En América Latina, este modelo de desarrollo asumió a finales del siglo xx la forma de extractivismo o producción de commodities, ya sea minería a cielo abierto, hidrocarburos o monocultivos para exportación (Hardt et al., 2013). En el modelo de desarrollo extractivista, la extracción de recursos naturales se realiza en gran volumen o alta intensidad, orientada esencialmente la exportación como materias primas sin procesar o con un procesamiento mínimo (Gudynas, 2015). Esta definición parte de una mirada local, pues la actividad extractiva está siempre anclada en un territorio específico, con la correlativa afectación de comunidades y alteración de ecosistemas, pero también incluye una dimensión global, pues la apropiación se orienta al comercio exterior.

Para Harvey (2001, 2007), el proyecto neoliberal de finales del siglo xx se explica por la crisis de sobreacumulación existente desde la década de los setenta; precisamente, una de las formas mediante las cuales el capital responde a las crisis es a través de una reacomodación geográfica destinada a la producción capitalista. Esta tesis, conocida como la acumulación por desposesión, supone un proceso continuo de despojo que requiere un análisis concreto de las historias, memorias y significados concretos de este. En otras palabras, para su análisis es necesario ubicarse histórica y geográficamente (Hart, 2016). En el caso de América Latina, esta reacomodación, como vimos, privilegia la explotación de recursos minero-energéticos y los monocultivos de exportación. Esta expansión capitalista requiere del Estado y sus instituciones, tales como la regulación del dinero, las intervenciones fiscales, el suministro de infraestructura, la represión militar, entre otros. Estos facilitan la constitución de un marco territorial y temporal para favorecer la acumulación de capital (Harvey, 1990; Sañudo Pazos \& Leal, 2018).

En ese sentido, el Estado juega un papel determinante en la consolidación del modelo de desarrollo al que adscribe a su población, especialmente en la creación de normas e instituciones que lo legitiman jurídica y simbólicamente, y en la definición de lo legal y lo ilegal, en función de apoyar actividades que considera rentables — como las

3 Ferrari (2016) define el capitalismo como “[...] la organización política, social y económica basada en la economía de mercado, la acumulación creciente de capital y combinada en Occidente con la democracia representativa" (p. 5). Asimismo, considera el vocablo 'neoliberal' como aquella ideología, denominada así en el mundo no desarrollado y 'neoconservadora' en el mundo desarrollado, cuyo eje central es la "[...] irrestricta libertad, apertura y autorregulación de los mercados" (Ferrari, 2016, p. 16). 
actividades extractivas- (Harvey, 1990; Sañudo Pazos \& Leal, 2018). La dimensión simbólica del poder ejercido por el Estado para mantener la prevalencia del modelo de desarrollo económico se encuadra en lo que Bourdieu (2014) denominó 'poder invisible', esto es, aquel poder ejercido de forma tan imperceptible que las personas sujetas a este desconocen su propia existencia. A través del poder simbólico, el Estado logra que sus ciudadanos interiorizan una forma de desarrollo sobre otra o, en términos de Bourdieu, el Estado crea un orden económico producto del contexto histórico actual e inculca en los ciudadanos las categorías de percepción y la conformidad moral necesarias para su legitimación ${ }^{4}$. En estados débiles, el control de las riquezas de sus territorios se ve cooptado por el poder de las corporaciones, capaces de restringir regulaciones, disminuir impuestos y definir políticas estatales en función del capital global (Comaroff \& Comaroff, 2000). Por ejemplo, en proyectos de megaminería el Estado pierde la soberanía sobre su territorio, y las empresas privadas usan un proceso hegemónico de discurso, gramsciano, para institucionalizar y naturalizar el modelo extractivo con eficacia simbólica global y local, usando el término de 'desarrollo o minería sostenible' dentro de la retórica desarrollista (Svampa \& Antonelli, 2009).

Muchos países interiorizaron el modelo de desarrollo extractivista, incluido Colombia, manteniendo su fuerza como un mito sobre el cual se ponen las esperanzas de un futuro mejor. Esta visión es hegemónica en el sentido de constituir un "[...] modo de vida ampliamente aceptado, amarrado institucionalmente y profundamente arraigado en las prácticas cotidianas de la gente; un modo de vida relacionado con determinadas ideas sobre el progreso" (Brand, 2014, p. 5) ${ }^{5}$. Esta concepción se asumió como una necesidad, como un camino que se debe seguir o, mejor, como el único camino para lograr números rimbombantes respecto de la producción, mientras se enmascaraba como la forma para dar a la población un mejoramiento en su bienestar. Adicionalmente, con la creación del binario desarrollo-subdesarrollo, se eliminó cualquier posibilidad de un mundo alternativo, y se inició el camino hacia la

\footnotetext{
4 Bourdieu (2014) menciona que el Estado impone en los agentes categorías de percepción que, al ser incorporadas en forma de estructuras mentales universales, se convierten en categorías dadas por sentado, que nadie piensa siquiera en cuestionar. Asimismo, uno de los principios de la eficacia simbólica estatal es que todo aquello que el Estado produce y codifica reposa en un sistema coherente y racional. Para el caso objeto de análisis, el modelo de desarrollo es una de esas categorías que, a través del poder simbólico, se vuelven incuestionables, ya que los individuos la perciben como una estructura coherente y racional (Bourdieu, 2014).

5 Brand (2014) lo denomina el 'modo de vida imperial'.
} 
homogeneización de las formas de vida (Esteva, 1996). Aun en pleno siglo XXI, el mito está plenamente instaurado en la conciencia de la mayoría de poblaciones, al punto de que la idea de que no hay alternativas al capitalismo tiene un gran grado de aceptación (De Sousa Santos \& Rodríguez Garavito, 2011; Gibson-Graham, 2006).

No obstante, el extractivismo fomenta los conflictos sociales por la exclusión que genera en las comunidades afectadas y la sobredimensión de la desigualdad y el trabajo informal (Hardt et al., 2013). En los modelos de desarrollo extractivista, con vocación exportadora, los estados han implementado formas violentas o de violencia simbólica para imponer a las comunidades una forma específica de vida. Sin embargo, aunque el capitalismo extractivista sea hegemónico, no excluye que se identifiquen otros modos de vida. Adicionalmente, si bien el modo de vida imperial reproduce las estructuras que contribuyen a las crisis sociales y ecológicas, y garantizan la simultaneidad de la continuidad y las crisis (Brand, 2014); esto no quiere decir que estas crisis no hayan actuado precisamente como develadoras de los modelos alternativos al desarrollo. Uno de estos modelos es el buen vivir, que no se relaciona específicamente con poblaciones colombianas, a pesar de estar enraizado en el mundo andino suramericano.

\section{EL BUEN VIVIR COMO MODELO \\ ALTERNATIVO AL DESARROLLO}

El buen vivir comparte con otros modelos de resistencia el cuestionamiento al desarrollo como metarrelato homogeneizante y universalizante. El buen vivir, de origen suramericano y anclado en la concepción andina de la vida, rescata el pensamiento indígena andino, principalmente ecuatoriano, peruano y boliviano, y se presenta como un nuevo proyecto político intercultural (Cuesta Caza, 2017). Este movimiento se ancla en el posdesarrollo y coincide con los demás modelos alternativos al desarrollo, como el de decrecimiento, en su crítica a la modernidad eurocéntrica, antropocéntrica, capitalista y economicista. Adicionalmente, se centra en la preservación o reencuentro con la naturaleza (Cuesta Caza, 2017).

Gudynas resalta que la idea del buen vivir no significa "[...] un regreso al pasado, sino la construcción de un futuro que es distinto al que determina el desarrollo convencional" (Gudynas, 2011, p. 8). Para este autor, el buen vivir es un concepto aglutinante y plural: sirve para agrupar diversas 
posturas, que también cuestionan el modelo de desarrollo y buscan cambios sustanciales apelando a otras relaciones entre las personas y el ambiente. Por esto, el buen vivir se presenta como una plataforma de llegada a un espacio común, que se origina en distintas ontologías y en diferentes culturas. Para este autor, el buen vivir no es exclusivo de los pueblos indígenas andinos, sino que supone una práctica construida desde la interculturalidad, para construir alternativas al desarrollo (Gudynas, 2011).

Como corolario de lo anterior, Gudynas (2011) menciona cinco puntos principales del buen vivir: en primer lugar, se abandona la pretensión del desarrollo como un proceso lineal; en segundo lugar, se plantea otra relación con la naturaleza, donde se le reconoce como sujeto de derechos; en tercer lugar, no se economizan las relaciones sociales ni mercantilizan los bienes y servicios; en cuarto lugar, se reconceptualiza el bienestar como algo que no depende solamente de la posesión de bienes e ingresos, y, en quinto lugar, el buen vivir no es una postura materialista, pues en este conviven otras espiritualidades y sensibilidades. Villalba (2013) adiciona a estos elementos la intención de decolonizar el conocimiento y proponer discusiones para encontrar convergencias entre las diferentes visiones. Además, existe un respeto al principio de reciprocidad en las relaciones comerciales y el gobierno local, con el fin de satisfacer las necesidades de los seres humanos y la naturaleza.

Cabe resaltar que el buen vivir no puede reducirse al concepto del 'bienestar' en torno al cual, desde los ochenta, interactúa la idea de 'desarrollo', como el fin último de todas las sociedades. La razón es que la noción de ‘desarrollo’ no existe en el pensamiento indígena andino (Cuesta Caza, 2017). El buen vivir supone un cambio más profundo en el conocimiento, la afectividad y la espiritualidad; una nueva forma de entender la relación entre humanos y no humanos, incluidos los animales, plantas, montañas, espíritus, entre otros (Chuji et al., 2019). Uno de los puntos más importantes del buen vivir es el reconocimiento de saberes que han sido rechazados por la colonialidad del poder propia de la modernidad y que, bajo el buen vivir, se vuelven legítimos (Chuji et al., 2019). El buen vivir se desvincula del crecimiento económico y se enfoca en la satisfacción completa de las necesidades humanas desde la austeridad. Con esto, se desplaza la centralidad que los humanos han tenido, su exclusiva representación política y fuente de valoración. El buen vivir nutre actualmente la resistencia al modelo de desarrollo tradicional (Chuji et al., 2019). 


\section{LA CORTE CONSTITUGIONAL, ¿REPRESENTANTE DEL BUEN VIVIR?}

El buen vivir se reconoce internacionalmente como un modelo alternativo al desarrollo de origen andino, cuyos principales expositores se ubican en Ecuador, Perú y Bolivia. No se encuentran referencias explícitas acerca del buen vivir de los pueblos indígenas andinos colombianos, aun cuando estos se han opuesto desde cada ontología al capitalismo extractivista adoptado por Colombia desde finales del siglo xx.

Sin embargo, la Corte Constitucional ha adoptado conceptos propios del buen vivir, a veces incluso refiriéndose específicamente a aquel ${ }^{6}$ en fallos en los que ha dirimido conflictos en los que el corporativismo se ha mostrado muy fuerte a la hora de establecer narrativas y consensos en torno a un modelo de desarrollo hegemónico (Comaroff \& Comaroff, 2010). En estos fallos, la Corte ha acudido a varios postulados de la Constitución de 1991 para cuestionar el modelo de desarrollo extractivista desde dos perspectivas. En primer lugar, parte de la pluralidad étnica y cultural como un pilar del estado social de derecho, que le permite garantizar la protección de comunidades minoritarias frente a proyectos que pretenden realizarse en sus territorios (Corte Constitucional, Sala Plena, expediente T-84771, sentencia SU-039, 1997), aun cuando el Gobierno nacional se haya adscrito a las locomotoras minero-energéticas como una única vía para mejorar el nivel de vida de la población en general. En segundo lugar, en concordancia con lo anterior, se basa en los principios que conforman la constitución ecológica y buscan proteger de forma integral el medio ambiente y garantizar "[...] un modelo de desarrollo sostenible (Corte Constitucional, Sala Cuarta de Revisión, expediente T-785, sentencia T-411, 1992). La Corte Constitucional ha reconocido 34 disposiciones que le dan el carácter ecológico a la Constitución de 1991 (Corte Constitucional, Sala Cuarta de Revisión, expediente T-785, sentencia T-411, 1992) 7 .

\footnotetext{
6 Véanse (Corte Constitucional, Sala Sexta de Revisión, expediente T-5.498.864, sentencia T-445, 2016; expediente T-4.353.004, sentencia T-080, 2015).

7 En esta sentencia se afirma:

[...] de una lectura sistemática, axiológica y finalista surge el concepto de 'constitución ecológica', conformado por las siguientes 34 disposiciones: || Preámbulo (vida), 2..$^{\circ}$ (fines esenciales del Estado: proteger la vida), 8. ${ }^{\circ}$ (obligación de proteger las riquezas culturales y naturales de la Nación), 11 (inviolabilidad del derecho a la vida), 44 (derechos fundamentales de los niños), 49 (atención de
} 
Para analizar dicha tendencia jurisprudencial, esta reflexión gira en torno a tres casos paradigmáticos: el primero, el conflicto entre el pueblo indígena úwa y la empresa petrolera Occidental; el segundo, la sentencia por medio de la cual se reconoció al río Atrato como sujeto de derechos, y el tercero, la sentencia que apoyó explícitamente a las consultas populares antimineras. Aunque solo en la tercera sentencia se plantea la discusión sobre el desarrollo mencionando explícitamente el concepto de 'buen vivir' y abandonando el antropocentrismo propio del capitalismo extractivista, en los dos primeros fallos también se nota una posición que comparte los postulados básicos de este modelo de desarrollo alternativo.

\section{El caso de Occidental de Colombia Inc. vs. u'wa}

El pueblo úwa se opuso a la realización de un proyecto de explotación de petróleo que se llevaría a cabo por Occidental de Colombia Inc. (Oxy) en el Bloque Samoré porque coincidía con su territorio ancestral. En ese conflicto se veía con claridad la actuación del Estado corporativista, cooptado por los intereses económicos, que "[...] entiende como hecho incuestionable que la decisión sobre el desarrollo del proyecto está en sus manos" (Serje, 2003, p. 106). De la misma manera, los indígenas ven la propuesta del Estado como una trampa: “[...] la explotación del territorio a cambio de los 'beneficios' del desarrollo; es decir de contaminación, vías 
de penetración, afluencia masiva de colonos, urbanización, invasión de sus territorios, deforestación, corrupción, militarización, extorsión, secuestro" (Serje, 2003, p. 106). Para aproximarse al conflicto, es preciso comprender que para los úwa la explotación de petróleo causa un desequilibrio en el mundo, ya que:

\section{[...] el petróleo (ruiría en lengua úwa) es vital para mantenerlo, es} la energía de la tierra, es generador de equilibrio entre el mundo de abajo y el intermedio que habitamos, también actúa como sostén de las lagunas y equilibra los temblores; y dado que la tierra es una deidad o cuerpo vivo, el daño cultural es inimaginable, ya que afecta a los dioses sobre los cuales ellos no tienen derecho ni autoridad para negociar, lo que perturba el equilibrio que debe existir entre los cuatro mundos de los que habla la cosmogonía úwa. (Cabra, 2014. p. 218).

En consecuencia, se trata de un conflicto por la forma de vida, el modelo de desarrollo, espiritualidades y relaciones con la naturaleza.

La Corte Constitucional intervino en este conflicto mediante la Sentencia SU-039 de 1997, con la ponencia del magistrado Antonio Barrera Carbonell, en la que decidió que el proyecto no había cumplido con la consulta previa prevista en el Convenio 169 de la Organización Internacional del Trabajo sobre pueblos indígenas y tribales, adoptado el 27 de junio de 1989 y ratificado por Colombia por medio de la Ley 21 de 1991.

Sin embargo, Semana publicó un informe especial en el 2007, según el cual:

[...] el tema de fondo no se relaciona con el procedimiento, ni con la metodología de la consulta, como pudiera deducirse de las intervenciones del gobierno. Por un lado, se aprecian visiones de mundo y perspectivas del desarrollo completamente distintas, que involucran posiciones, expectativas y actitudes divergentes sobre el papel del Estado, la inclusión y la pervivencia de los pueblos indígenas, el diálogo entre culturas y la interpretación de las leyes, que hacen muy complejo el problema y cuestionan hasta el mismo modelo de un Estado que, pese a los preceptos constitucionales, no termina de hacerse multicultural (Restrepo, 2007).

Efectivamente, un análisis más minucioso de la sentencia revela que la Corte sí se refirió a que "[e]l reconocimiento de la diversidad étnica y 
cultural en la Constitución supone la aceptación de la alteridad ligada a la aceptación de multiplicidad de formas de vida y sistemas de comprensión del mundo diferentes de los de la cultura occidental"(Corte Constitucional, Sala Plena, expediente T-84.771, sentencia SU-039, 1997). Para esto, exigió la consulta previa como mecanismo de concertación y no simplemente de notificación a la comunidad sobre el proyecto de exploración y explotación de recursos naturales (Corte Constitucional, 1997).

Lo destacable, en este caso, fue que la Corte, aunque con mayor énfasis en asuntos legales, admitió que un proyecto extractivista no podía pasar por encima de la cosmogonía y formas de vida particulares del pueblo úwa, sin al menos el cumplimiento de la consulta previa. Contrastando los elementos principales del buen vivir en (Gudynas, 2011), encontramos que la Corte: (1) se apartó del metarrelato homogeneizante del desarrollo petrolero, y (2) admitió la necesidad de consultar al pueblo úwa en una aceptación tácita de que aquel tenía una forma de entender el petróleo totalmente distinto al hegemónico, especialmente al no considerarlo un bien mercantil, derivado de otras espiritualidades o sensibilidades. En ese sentido, la posición de la Corte coadyuvó a los úwa en el conflicto que, temporalmente ${ }^{8}$, se resolvió en su favor, con el abandono del proyecto por parte de Oxy.

\section{El río Atrato como sujeto de derechos}

En la Sentencia T-622 del 2016, con la ponencia del magistrado Jorge Iván Palacio Palacio, la Corte Constitucional resolvió en sede de tutela una petición de amparo de los derechos fundamentales de comunidades étnicas afrocolombianas e indígenas que viven en la cuenca del río Atrato. Con la demanda se pretendía detener el uso intensivo y a gran escala de diversos métodos de extracción minera y explotación forestal ilegales, que usaban incluso sustancias tóxicas, lo cual afectaba, entre otros, el equilibrio natural de los territorios, las actividades ancestrales como la agricultura de subsistencia basada en el policultivo, la pesca con flechas y atarrayas, y la minería artesanal. A su vez, se perjudicaba un espacio que las comunidades no solo han considerado como su territorio, sino el espacio para reproducir la vida y recrear la cultura: la cuenca del río Atrato.

8 Este conflicto puede considerarse abierto por la posterior pretensión de Ecopetrol a realizar exploraciones y explotaciones en territorios de los u'wa, una vez Oxy cesó en su interés en el bloque Samoré. 
Para resolver este conflicto la Corte optó por un enfoque ecocéntrico como paradigma de la relación con la naturaleza. Según esta perspectiva, la tierra no le pertenece al hombre, sino, por el contrario, el hombre pertenece a la tierra, como cualquier otra especie. Esto supone que el ser humano no es dueño de las demás especies, de la biodiversidad, de los recursos naturales ni del destino del planeta. De esta teoría se deriva que la naturaleza "[...] es un auténtico sujeto de derechos que deben ser reconocidos por los Estados y ejercidos bajo la tutela de sus representantes legales, verbigracia, por las comunidades que la habitan o que tienen una especial relación con ella" (Corte Constitucional, Sala Sexta de Revisión, expediente T-5.016.242, sentencia T-622, 2016). A partir del enfoque ecocéntrico, la Corte plantea:

[...] el desafío más grande que tiene el constitucionalismo contemporáneo en materia ambiental, consiste en lograr la salvaguarda y protección efectiva de la naturaleza, las culturas y formas de vida asociadas a ella y la biodiversidad, no por la simple utilidad material, genética o productiva que estos puedan representar para el ser humano, sino porque al tratarse de una entidad viviente compuesta por otras múltiples formas de vida y representaciones culturales, son sujetos de derechos individualizables, lo que los convierte en un nuevo imperativo de protección integral y respeto por parte de los Estados y las sociedades (Corte Constitucional, Sala Sexta de Revisión, expediente T-5.016.242, sentencia T-622, 2016).

La Corte Constitucional cita uno de los apartes del texto Encountering Development: The Making and Unmaking of the Third World de Arturo Escobar, para plantear explícitamente su crítica al desarrollo:

[...] el concepto de desarrollo era —y continúa siendo en gran parteuna aproximación política centralista, jerárquica, etnocéntrica y tecnocrática que entiende a las poblaciones y a la cultura como objetos abstractos y como figuras estadísticas que deben acomodarse de acuerdo a las prioridades del progreso. Este modelo de desarrollo ha sido concebido no como un proceso cultural, sino por el contrario como un sistema universal de intervenciones técnicas cuyo propósito es entregar recursos, bienes y servicios a los pueblos (que se juzguen dentro de este criterio) con mayores necesidades. Es por ello que no sorprende que el desarrollo se haya convertido en una fuerza tan destructiva para las 
culturas del llamado Tercer Mundo, irónicamente, en nombre de los mejores intereses de los pueblos (Corte Constitucional, Sala Sexta de Revisión, expediente T-5.016.242, sentencia T-622, 2016).

De igual forma, la Corte se adscribe a otras alternativas al desarrollo con base en la tesis de Escobar, según la cual:

[...] diversas experiencias a nivel mundial han demostrado que el modelo de desarrollo occidental (basado en la concepción del crecimiento económico) es la peor opción para las comunidades étnicas. Para acceder a modelos alternativos como el posdesarrollo las comunidades necesitan experimentar con estrategias alternativas de producción, y simultáneamente desarrollar una semiótica de resistencia a la reestructuración moderna de la naturaleza y de la sociedad (Corte Constitucional, Sala Sexta de Revisión, expediente T-5.016.242, sentencia T-622, 2016).

Con base en lo anterior, la Corte considera necesario dar un paso adelante en la jurisprudencia hacia la protección constitucional del río Atrato, declarándolo sujeto de derechos. Adicionalmente, se adscribe a la bioculturalidad, resalta la unidad entre naturaleza y especie humana, y supera, con esto, uno de los principales binarios de la modernidad. Esta relación, para la Corte, se expresa, entre otros:

[...] (ii) los múltiples modos de vida expresados como diversidad cultural [que] están inextricablemente vinculados con la diversidad de ecosistemas y territorios; (ii) la riqueza expresada en la diversidad de culturas, prácticas, creencias y lenguajes es el producto de la interrelación coevolutiva de las comunidades humanas con sus ambientes y constituye una respuesta adaptativa a cambios ambientales; (iii) las relaciones de las diferentes culturas ancestrales con plantas, animales, microorganismos y el ambiente contribuyen activamente a la biodiversidad; (iv) los significados espirituales y culturales de los pueblos indígenas y de las comunidades locales sobre la naturaleza forman parte integral de la diversidad biocultural; y (v) la conservación de la diversidad cultural conduce a la conservación de la diversidad biológica, por lo que el diseño de política, legislación y jurisprudencia debe enfocarse por la conservación de la bioculturalidad (Corte 
Constitucional, Sala Sexta de Revisión, expediente T-5.016.242, sentencia T-622, 2016).

Entre los aspectos mencionados por la Corte hay varios que comparten elementos constitutivos del buen vivir: la naturaleza es sujeto de derechos; el reconocimiento de otros modos de vida, en este caso de poblaciones afrocolombianas e indígenas; la paridad con los seres vivos no humanos; la eliminación de la dualidad naturaleza-cultura, propia de la modernidad, y el reconocimiento de los significados espirituales y culturales de los pueblos indígenas y afrocolombianos.

En ese sentido, este fallo es paradigmático por su oposición explícita al desarrollo extractivista lineal y por acudir abiertamente a teorías alternativas al desarrollo, para otorgar la protección de un ser vivo no humano.

\section{El caso de las consultas populares antimineras}

En la línea jurisprudencial que apoyó la realización de las consultas populares antimineras, la sentencia T-445 del 2016, del magistrado ponente Jorge Iván Palacio Palacio, resalta una abierta posición contrahegemónica frente el modelo de desarrollo minero impuesto desde arriba, y al que se ha adscrito Colombia en los últimos años. Esta sentencia tiene dos elementos clave en la lucha de la resistencia contra el extractivismo: la justicia social ambiental y el derecho a un desarrollo alternativo (Corte Constitucional, Sala Sexta de Revisión, expediente T-5.498.864, sentencia T-445, 2016). Sobre la justicia social ambiental, la Corte estableció que "[p]ara garantizar que la justicia social ambiental no sea anulada o menoscabada bajo el rótulo de 'desarrollo', debe garantizarse en el mayor nivel posible la participación de los afectados" (Corte Constitucional, Sala Sexta de Revisión, expediente T-5.498.864, sentencia T-445, 2016). Se avalan con esto el derecho que le asistía a las comunidades directamente involucradas con un proyecto mineroenergético de decidir sobre las actividades que aceptaban en su territorio.

Sobre el segundo aspecto, en la sentencia se reitera otro fallo de Jorge Iván Palacio Palacio (Corte Constitucional, Sala Sexta de Revisión, expediente T-4.353.004, sentencia T-080, 2015), en el cual se había anticipado la necesidad de crear un nuevo modelo de desarrollo, a partir de la denuncia de Boaventura de Sousa Santos (2014, p. 14) sobre el pensamiento hegemónico detrás del concepto aparentemente neutral y positivo de 'desarrollo'. Para tal efecto, en ambos fallos se enfatiza en: 
La cada vez más creciente reacción del "Sur global" por superar la forma acrítica, vertical y hegemonizante en que se ha asumido el desarrollo, ha derivado en proyectos alternativos de convivencia y buen vivir, más allá de los parámetros dispuestos por la lógica del mercado. Es una apuesta que exalta las "ideas de reciprocidad, solidaridad y complementariedad vigentes tanto en las relaciones entre los seres humanos como en las relaciones entre los humanos y la naturaleza (Corte Constitucional, Sala Sexta de Revisión, expediente T-5.498.864, sentencia T-445, 2016).

De igual forma, la sentencia cita a Arturo Escobar en una reflexión sobre el posdesarrollo. Allí, explícitamente se aboga por que el desarrollo cese de ser el principio central que organiza la vida económica y social. Según esta idea, en esta clase de existencia se deben desarticular las premisas de la modernización, la explotación de la naturaleza como un ser no vivo, los mercados, la exportación y la acción individual. A partir de este marco teórico, la sentencia expresamente manifiesta lo siguiente:

Tenido en cuenta lo anterior, es clara la necesidad de repensar creativamente un nuevo modelo de desarrollo que tenga como centro el respeto de la dignidad de la persona humana y sus derechos fundamentales; que responda a las necesidades actuales pero que garantice su sostenibilidad para las generaciones futuras; no es aceptable un modelo de riqueza para hoy y pobreza para mañana. Un modelo con criterios morales y éticos, que haga de Colombia un Estado social de derecho, que responda a las necesidades de toda la población (Corte Constitucional, Sala Sexta de Revisión, expediente T-5.498.864, sentencia T-445, 2016).

A partir de lo anterior, el magistrado no solo cuestiona los métodos para obtener recursos públicos cuando aquellos tienen altos costos sociales o medioambientales, sino que también disputa el irreflexivo optimismo con el que se asumen los macroproyectos económicos que generan empobrecimiento y pauperización del entorno más cercano. Como se observa, en esta sentencia la Corte abiertamente toma una posición contrahegemónica respecto del modelo de desarrollo extractivista, y lo hace de forma manifiesta a través del lenguaje con el que transmite su mensaje: hace un uso consciente del discurso para plantear un conflicto por el modelo de desarrollo, nota las posiciones encontradas y el poder que tienen las corporaciones en el país, y toma partido por una opción 
posdesarrollista. La Corte problematiza el extractivismo desde perspectivas sociales y ecológicas, saliéndose del formalismo jurídico.

Adicionalmente, esta sentencia, como la anterior, cuestiona la idea de que la humanidad es señora de la naturaleza, la cual, a su vez, sería un objeto externo inagotable y puesto a su entera disposición. En ese sentido, la Corte manifiesta su preocupación por salvaguardar los elementos y componentes de la naturaleza de los efectos nocivos del modelo de desarrollo extractivista. El razonamiento no acude a su papel en la supervivencia del ser humano, sino a sus derechos intrínsecos (Corte Constitucional, Sala Sexta de Revisión, expediente T-5.498.864, sentencia T-445, 2016). Para la Corte, entonces, los seres vivos no humanos tienen valor por sí mismos y no por su relación con el hombre: "Solo a partir de una actitud de profundo respeto con la naturaleza y sus integrantes es posible entrar a relacionarse con ellos en términos justos y equitativos, abandonando todo concepto que se limite a lo utilitario o eficientista" (Corte Constitucional, Sala Sexta de Revisión, expediente T-5.498.864, sentencia T-445, 2016).

En esta sentencia, entonces, la Corte arbitra un conflicto de intereses económicos y de poder, tomando un explícito partido por los modelos alternativos al desarrollo. En efecto, exhibe claramente cuestionamientos al modelo de desarrollo capitalista, a partir de elementos propios del buen vivir, aunque en el conflicto resuelto no participan grupos indígenas, sino movimientos sociales campesinos. En particular, en el fallo se resalta el abandono del antropocentrismo, pues la Corte literalmente expone que "[...] el humano es un ser más en el planeta y depende del mundo natural" (Corte Constitucional, Sala Sexta de Revisión, expediente T-5.498.864, sentencia T-445, 2016). Según esto, la naturaleza es un sujeto de derechos, lo que reitera la posición ya expuesta en el caso del río Atrato y la autonomía para que las comunidades decidan otros modelos alternos al desarrollo.

\section{CONCLUSIONES}

Una visión ampliada del buen vivir como la propuesta por Gudynas (2011) permite entender esta práctica como un concepto plural y aglutinante de ontologías críticas al desarrollo, no exclusiva de los pueblos indígenas andinos, sino construidas a partir de la interculturalidad. El buen vivir no se presenta como una visión reduccionista; antes bien, se construye 
precisamente a partir de la pluralidad (Villalba, 2013). En la literatura académica no se observa que Colombia sea un referente del buen vivir, a pesar de la diversidad étnica y cultural presente en su territorio. Derivado de lo anterior, Colombia tampoco ha tenido posibilidades de que gobiernos progresistas coopten el concepto, como sucedió en Ecuador y Bolivia. De hecho, en Colombia, el proyecto de desarrollo capitalista extractivo escasamente se ha cuestionado, y, por el contrario, el bienestar de la sociedad en general se ha puesto en manos de la locomotora mineroenergética ${ }^{9}$. El país, entonces, hace parte del mito capitalista que ve al desarrollo como el único camino para el bienestar social.

A pesar de esas dos condiciones en contra de la visibilidad de alternativas al desarrollo, la Corte Constitucional ha jugado un papel importante en poner en el centro de la discusión modelos contrahegemónicos, pues ha actuado como árbitro en conflictos que involucran intereses económicos extractivos.

En los ejemplos analizados en este trabajo se observa una aproximación de la Corte a los conceptos propios del buen vivir mencionados por Gudynas (2011): la naturaleza como sujeto de derechos, en los casos del río Atrato y las consultas populares; la legitimación de otras formas de vida, espiritualidades y sensibilidades, en el caso del pueblo úwa y las comunidades del río Atrato, y la desmercantilización de la naturaleza, transversal en los tres fallos. De igual forma, en todas las sentencias se nota una crítica al modelo de desarrollo adoptado por la rama ejecutiva.

Así mismo, la Corte reconoce tácitamente saberes que han sido rechazados por la colonialidad epistemológica, de tal forma que su intervención en los conflictos se constituye en una descolonización para abandonar la superioridad occidental, respetando la diversidad de las demás culturas, en los términos de Gudynas (2011) y Chuji et al. (2019). Esta legitimidad de otros saberes es también propia del buen vivir. Las tres sentencias tienen como punto común la oposición a la forma economicista del desarrollo. Sin embargo, la Corte se cuida de dejar abiertas las posibilidades a las diversas formas de vida que cada comunidad plantea,

9 Pueden observarse, como ejemplo, el Plan Nacional de Desarrollo 2006-2010. Estado comunitario: prosperidad para todos, de Álvaro Uribe Vélez; el Plan Nacional de Desarrollo 2010-2014. Prosperidad para todos y el Plan Nacional de Desarrollo 2014-2018. Todos por un nuevo país, estos dos últimos de Juan Manuel Santos. De hecho, en la sentencia SU-085 del 2018, la misma Corte Constitucional reconoce que "la explotación del 'subsuelo ha sido postulado como dinamizador del país"' (Corte Constitucional, 2018). 
pues en los tres casos analiza comunidades diferentes (indígenas — úwas y río Atrato-, afrocolombianos — río Atrato-y campesinas — consultas populares-), sin intentar imponer un saber o visión del mundo sobre otro, esto es, respetando y legitimando la diversidad de cada cultura.

Finalmente, más allá de la discusión sobre si los fallos solo tienen una eficacia simbólica ${ }^{10}$, lo cierto es que abren la puerta a una construcción de un mundo diferente y que la Constitución es un instrumento legal suficiente para plantear estas nuevas posibilidades. En ese sentido, la Constitución tiene los elementos para plantear modelos alternativos al desarrollo, como el buen vivir, por el reconocimiento que hace de la pluralidad étnica y cultural como eje central del estado social de derecho, en concordancia con la protección especial del medio ambiente.

\section{REFERENCIAS}

Bourdieu, P. (2014). On the State. Lectures at the Collège de France, 1989-1992. Policy Press.

Brand, U. (2014). Crisis socioecológica y modo de vida imperial. Crisis y continuidad de las relaciones sociedad-naturaleza en el capitalismo. Saskab. Revista de Discusiones Filosóficas desde acá, 7, 1-27.

Cabra, D. (2014). Megaproyecto petrolero y violación de derechos humanos en el caso de la comunidad indígena u'wa. Jurídicas, 11(1), 206-223.

Castoriadis, C. (1991). Reflexiones sobre el desarrollo y la racionalidad. En F. Giraldo \& F. Viviescas (Eds.), El despertar de la modernidad (pp. 90-122). Editorial Foro Nacional por Colombia.

Chuji, M., Rengifo, G., \& Gudynas, E. (2019). Buen vivir. En A. Kothari, A. Salleh, A. Escobar, F. Demaria, \& A. Acosta (Eds.), Pluriverse. A Post-Development Dictionary (pp. 112-114). Tulika Books.

Comaroff, J., \& Comaroff, J. L. (2000). Millenial Capitalism: First Thoughts on a Second Coming. Public Culture, 12(2), 291-343. https://doi. org/10.1215/08992363-12-2-291

Corte Constitucional. Sala Cuarta de Revisión. (1992, 17 de junio). Sentencia T-411. [MP Alejandro Martínez Caballero] https://www.corteconstitucional. gov.co/relatoria/1992/t-411-92.htm

Corte Constitucional. Sala Plena. (1997, 3 de febrero). Sentencia SU-039. [MP Antonio Barrera Carbonel] https://www.corteconstitucional.gov.co/ relatoria/1997/su039-97.htm

10 Al respecto, se ha cuestionado si la declaratoria de sujetos de derechos de los ríos o la Amazonía es un instrumento eficaz para garantizar la conservación, protección y restauración de la naturaleza (Semana Sostenible, 2020). 
Corte Constitucional. Sala Sexta de Revisión. (2016, 19 de agosto). Sentencia

T-445. [MP Jorge Iván Palacio Palacio.] https://www.corteconstitucional.gov. co/relatoria/2016/t-445-16.htm

Corte Constitucional. Sala Sexta de Revisión. (2016, 10 de noviembre). Sentencia T-622. [MP Jorge Iván Palacio Palacio.] https://www.corteconstitucional.gov. co/relatoria/2016/t-622-16.htm

Corte Constitucional. Sala Plena. (2018, 11 de octubre). Sentencia SU-095. [MP Cristina Pardo Schlesinger.] https://www.corteconstitucional.gov.co/ relatoria/2018/SU095-18.htm

Cuesta Caza, J. (2017). Sumak Kawsay: El buen vivir antes de ser el buen vivir. En M. Delgado Cabeza \& A. Lara Galicia (Eds.), El extractivismo en América Latina. Dimensiones económicas, sociales, políticas y culturales (pp. 356-368). Instituto de Estudios sobre América Latina de la Universidad de Sevilla.

De Sousa Santos, B. (2014). Derechos humanos, democracia y desarrollo. Centro de Estudios de Derecho, Justicia y Sociedad, Dejusticia. https://www.dejusticia. org/wp-content/uploads/2017/04/fi_name_recurso_646.pdf

De Sousa Santos, B. \& Rodríguez Garavito, C. (2011). Introducción. Para ampliar el canon de la producción. En Producir para vivir. Los caminos de la producción no capitalista (pp. 15-61). Fondo de Cultura Económica.

Esteva, G. (1996). Desarrollo. En W. Sachs (Ed.), Diccionario del desarrollo. Una guía del conocimiento como poder (pp. 52-78). Editorial Pratec.

Ferrari, C. (2016). Capitalismo. Crisis, cambios y evolución en el siglo XXI. Pontificia Universidad Javeriana.

Gibson-Graham, J. K. (2006). A postcapitalist politics. University of Minnesota Press. Gudynas, E. (2011). Buen vivir. Germinando alternativas al desarrollo. América Latina en Movimiento, (462), 1-20.

Gudynas, E. (2015). Extractivismos: Ecologia, economia y politica de un modo de entender el desarrollo y la naturaleza. Centro de Documentación e Información Bolivia.

Hardt, M., Reyes, Á., \& Zibechi, R. (2013). La construcción de otro mundo en América Latina. En Preservar y Compartir (pp. 15-66). Mar Dulce.

Hart, G. (2016). Desnaturalizar el despojo: Una etnografía crítica en la era del resurgimiento del imperialismo. Revista Colombiana de Antropología, 52(2), 139-173. https://doi.org/10.22380/2539472x42

Harvey, D. (1990). The Condition of Postmodernity. Blackwell.

Harvey, D. (2001). Spaces of Capital. Towards a Critical Geography. Routledge.

Harvey, D. (2007). La acumulación por desposesión. En El nuevo imperialismo (pp. 99-129). Akal.

Kothari, A., Salleh, A., Escobar, A., Demaria, F., \& Acosta, A. (2019). Introduction: Finding Pluverse Paths. In A. Kothari, A. Salleh, A. Escobar, F. Demaria, \& A. Acosta (Eds.), Pluriverse. A Post-Development Dictionary (pp. xxi-xl). Tulika. https://doi.org/10.1017/CBO9781107415324.004

Rasch, E. D. (2012). Transformations in Citizenship. Local Resistance against Mining Projects in Huehuetenango (Guatemala). Journal of Developing Societies, 28(2), 159-184. https://doi.org/10.1177/0169796X12448756 
Rasch, E. D. (2017). Citizens, criminalization and violence in natural resource conflicts in Latin America. European Review of Latin American and Caribbean Studies, 2017 (103), 131-142. https://doi.org/10.18352/erlacs.10193

Restrepo, O. L. (2007). Por qué el pueblo u'wa se niega a la exploración petrolera en su territorio. Semana. https://www.semana.com/on-line/articulo/por-quepueblo-uwa-niega-exploracion-petrolera-su-territorio/83954-3

Sañudo Pazos, M. F. \& Leal, J. (Eds.). (2018). Aproximaciones críticas a la relación Estado y territorio en contextos de globalización neoliberal. Editorial Clacso.

Semana Sostenible. (2020). ¿Sirve o no declarar a la naturaleza como sujeto de derechos? Semana. https://sostenibilidad.semana.com/impacto/articulo/ sirve-o-no-declarar-a-la-naturaleza-como-sujeto-de-derechos-i-colombiahoy $/ 54357$

Serje, M. (2003). ong, indios y petróleo. El caso u'wa a través de los mapas del territorio en disputa. Bulletin de l'Institut Français d'études Andines, 32 (1), 101131. https://doi.org/10.4000/bifea.6398

Svampa, M. \& Antonelli, M. (2009). Mineria transnacional, narrativas de desarrollo y resistencias sociales. Biblos.

Villalba, U. (2013). Buen Vivir vs Development. A Paradigm Shift in the Andes? Third World Quarterly, 34(8), 1.427-1.442. https://doi.org/10.1080/01436597.2 013.831594

Walter, M. \& Urkidi, L. (2017). Community Mining Consultations in Latin America (2002-2012). The Contested Emergence of a Hybrid Institution for Participation. Geoforum, 2017 (84), 265-279. https://doi.org/10.1016/j. geoforum.2015.09.007 